\title{
Prediction of Postradical Prostatectomy Urinary Incontinence Through the Combination of the Urethral Pressure Profile With Electromyography of the Urethral Sphincter
}

\author{
Jonathan Rodríguez Talavera ${ }^{1}$, Begoña Ballesta Martínez ${ }^{1}$, Melania Santacruz Perez ${ }^{1}$, Manuel Felipe Ravina Pisaca ${ }^{1}$, \\ David Castro Díaz ${ }^{2}$ \\ ${ }^{1}$ Department of Urology, Hospital Universitario Nuestra Señora de Candelaria, Santa Cruz de Tenerife, Spain \\ ${ }^{2}$ Department of Urology, Hospital Universitario de Canarias, Santa Cruz de Tenerife, Spain
}

Purpose: We tested the hypothesis that the urethral pressure profile, in combination with electromyography of the urethral sphincter, may be useful as a predictor of urinary incontinence after radical prostatectomy (RP). The aim of this study was to assess whether the combination of these tests resulted in an improved tool for the prediction of post-RP urinary incontinence. Methods: Patients with indications for RP were included. The urethral pressure profile, including prostatic and sphincter components for maximum urethral closure pressure (MUCP) and functional urethral length, was recorded in combination with needle electromyography of the urethral sphincter. The mean and maximum amplitude of waves were measured twice: 1 month before RP and 6 months after the procedure. The 1-hour pad test was conducted in parallel with other tests. Patients completed the International Consultation on Incontinence Questionnaire - Short Form (ICIQ-SF). The relationship of the results of the tests with post-RP urinary incontinence was studied. Age, urodynamic parameters, pathologic stage, and surgical technique were recorded for analysis as potential confounding factors.

Results: Nineteen patients were included within the 1-year study period. Their mean age was 63 years. According to the 1-hour pad test and ICIQ-SF, $42.1 \%$ of the sample had urinary incontinence after RP. Prostate MUCP with the mean and during-stress amplitude of waves predicted post-RP urinary incontinence with a sensitivity of $87.5 \%(\mathrm{P}=0.002)$ in our model. Age, urodynamic parameters, pathological stage, and surgical technique were not related to incontinence after surgery.

Conclusions: The combination of the urethral pressure profile (prostatic MUCP) and electromyography of the urethral sphincter might be a useful prognostic predictor of post-RP urinary incontinence.

Keywords: Urodynamics; Urinary incontinence, Stress; Electromyography; Prostatectomy

- Research Ethics: This study was approved by Ethics Committee of the University Hospital Nuestra Señora de Candelaria (registration number: PI-23-14).

- Conflict of Interest: No potential conflict of interest relevant to this article was reported.

\section{INTRODUCTION}

The oncological outcomes of radical prostatectomy (RP) and radiotherapy for the treatment of localized prostate cancer have shown no differences [1]. The goal of RP by any approach is the eradication of cancer, while preserving continence and potency if possible. Post-RP urinary incontinence is an important quality of life concern $[2,3]$.

Corresponding author: Begoña Ballesta Martínez (iD https://orcid.org/0000-00018567-0545

Department of Urology, Hospital Universitario Nuestra Señora de Candelaria, Carretera Gral del Rosario, Urologia, 1st floor. 38010, Santa Cruz de Tenerife, Spain Email: bballestamartinez@gmail.com

Submitted: January 19, 2021 / Accepted after revision: March 15, 2021 
The prediction of post-RP urinary incontinence might help consistently in the treatment selection for patients with localized prostate cancer who are eligible for both RP and radiotherapy. Although other factors such as detrusor overactivity or lowered bladder accommodation may contribute [4], the explanation for why urgency is reported either alone or combined by certain patients is that post-RP urinary incontinence is mainly a type of stress urinary incontinence that usually occurs due to sphincter dysfunction after surgery [5].

There are 4 main available techniques for the evaluation of urethral sphincter function after RP: electromyography, perfusion sphincterotomy, magnetic resonance imaging (MRI), and urethral pressure profile studies. However, there is a lack of effective predictive tests and indicators. None of the diagnostic tools for the evaluation of urethral sphincter before and after RP have proven to show solid prognostic value. Studies of the urethral pressure profile alone established that the maximum urethral closure pressure (MUCP) and functional urethral length (FUL) decrease after RP. A high preoperative MUCP is associated with a high likelihood of continence recovery [6]. It has been suggested that post-RP FUL reduction may be an important predictor of continence recovery [6].

Electromyography of the urethral sphincter has not proved to predict which patients will recover from urinary incontinence after RP $[7,8]$. Perfusion sphincterometry is useful for the study of post-RP urinary incontinence, but it is performed after surgery. It has been shown that the majority of patients with established post-RP urinary incontinence have abnormal function in the urethral sphincter after surgery when measuring the urine leaking point during the Valsalva maneuver. Nonetheless, no relationship between that finding and the clinical severity of urinary incontinence has been reported, and the relationship between the results of perfusion sphincterometry and the measurement of MUCP in the urethral pressure profile studies is weak $[9,10]$. The sphincter length, which is probably directly related to faster and more reliable continence recovery after RP, can be quantified by measurements with MRI $[11,12]$. Ikarashi et al. [13] suggested a 12-mm cutoff value of the membranous urethral length, while Rico et al. [14] set it at $10 \mathrm{~mm}$. Nevertheless, in most studies, measurements have been made both prior to the procedure and retrospectively [11-15].

Furthermore, the data on the urethral pressure profile [16-20] suggest that MUCP and FUL decrease after RP. A high presurgical MUCP is related to a high probability of continence recovery. The relation between presurgical FUL and its decrease after RP could be an important predictor of continence recovery. However, other factors such as neurophysiological failure and age-dependent sphincter atrophy could also have an impact on continence recovery, because different post-RP continence outcomes in patients with similar FUL have been reported.

We tested the hypothesis that the combination of the urethral pressure profile and electromyography of the sphincter may be useful as a predictor of urinary incontinence after RP. The primary endpoint of the study was to assess whether there is a relationship between alterations in the combination of these 2 tests and the presence of postprostatectomy incontinence.

\section{MATERIALS AND METHODS}

\section{Experiments and Patients}

This prospective study was carried out between July 2014 and January 2017. The inclusion criteria were all patients with clinical indications for RP who provided written informed consent to participate in the study. No exclusion criteria were set. A urodynamic study with urethral profile and simultaneous needle electromyography in the lithotomy position were performed 1 month before RP and 6 months after surgery. An MMS Solar Silver cystometry device was used. A triple-lumen urethral pressure profile $7 \mathrm{~F}$ catheter was placed in the bladder and a $4.5 \mathrm{~F}$ balloon catheter was placed in the rectum. Before cystometry, isolated uroflowmetry and measurement of postvoid urine volume were performed. The catheter was removed with an automatic retractor at a constant speed of $1 \mathrm{~mm} / \mathrm{sec}$ when a minimal voiding volume of $200 \mathrm{~mL}$ was registered. The perfusion speed was set at $5 \mathrm{~mL} / \mathrm{min}$ for the set of urethral pressure measurements according to the Brown and Wickham technique.

Urinary continence was defined as urinary leakage $\leq 1 \mathrm{~g}$ within the 1-hour pad test. Needle electromyography (with a Medelec Synergy 10-channel device; Oxford Instruments, Abington, UK) was performed using a subdermal needle with a single ground electrode and a needle connector $(50 \mathrm{~mm} \times 26 \mathrm{G}$; Natus Neurology, Middleton, WI, USA). Recordings were made both at rest and when asking the patients to perform a maximum voluntary urethral sphincter contraction. The increase in muscle activity and the density of the interference pattern in the muscle were recorded.

In order to place the electrode for electromyography, a digital rectal examination was performed to determine the location of the apex of the prostate. Then, using a perineal approach, the electrode was directed into the apex of the prostate $2-3 \mathrm{~cm}$ 
deep through the bulbocavernosus muscle.

The electrode location setting for postsurgery investigations was determined by monitoring motor unit potentials and a visual inspection of acute signals on electromyography.

\section{Data Recorded}

Age, involuntary detrusor contractions assessed by urodynamic study, the surgical approach, tumoral stage, and urethral pressure profile were recorded. The urethral pressure profile included MUCP and FUL. Presurgical MUCP and FUL were subdivided into prostatic urethra (p-MUCP and p-FUL) and urethral sphincter (s-MUCP and s-FUL) measurements (Fig. 1). In the quantitative electromyographic study, the number of waves was measured and recorded at 3 points: resting amplitude, mean amplitude, and during-stress amplitude. The patients completed the International Consultation on Incontinence Questionnaire - Short Form (ICIQ-SF). Urine leakage was quantified using the 1-hour pad test and the number of pads used per day.

\section{Statistical Analysis}

A quantitative study of electromyography of the sphincter was performed. A quantitative analysis of the interference patterns was also carried out, with measurements of motor units and amplitude analysis.

IBM SPSS Statistics ver. 21.0 (IBM Co., Armonk, NY, USA) and Excel 2016 (Microsoft Corp., Redmond, WA, USA) were used to generate graphics and conduct the statistical analysis. Statistical significance was set as a P-value below $0.05(\alpha=5 \%)$. Comparisons for continuous variables between groups (continent vs. incontinent) were made with the Student t-test for in- dependent samples if variables had a normal distribution. The Fisher and Mann-Whitney U-tests were used if a normal distribution was not present.

Two possible models were tested. One subdivided independent variables into sphincteric and prostatic components, and the other included all (nonsubdivided) independent variables. In cases where there was a single remaining variable affecting the results of the pad test, the possibility of using a quadratic or exponential model was studied using the $\mathrm{R}^{2}$ coefficient of determination.

Multiple logistic regression was used to predict urinary incontinence through the Wald method for backward selection of variables using the standard entry and exit values of 0.05 and 0.10 respectively. When applying the logistic regression, the probability of incontinence after surgery was set as $p$ and the linear predictor was set as $\eta$. The linear predictor is also known as logit p or the Napierian logarithm of p between 1-p, and is obtained by applying logistic regression. The covariables and variables initially considered were p-MUCP, s-MUCP, p-FUL, s-FUL, wave amplitude (resting, mean, and during stress), age, uninhibited detrusor contractions (UDC), surgical technique, and tumoral stage defined using the TNM system. The performance of the predictive models for urinary incontinence was analyzed using receiver operating characteristic (ROC) curves and the area under the ROC (AUROC). The confidence interval for the AUROC was $95 \%$. The sensitivity of the test was calculated for a false positive rate of $10 \%$.

\section{RESULTS}

Nineteen patients were included in the study. The patients were

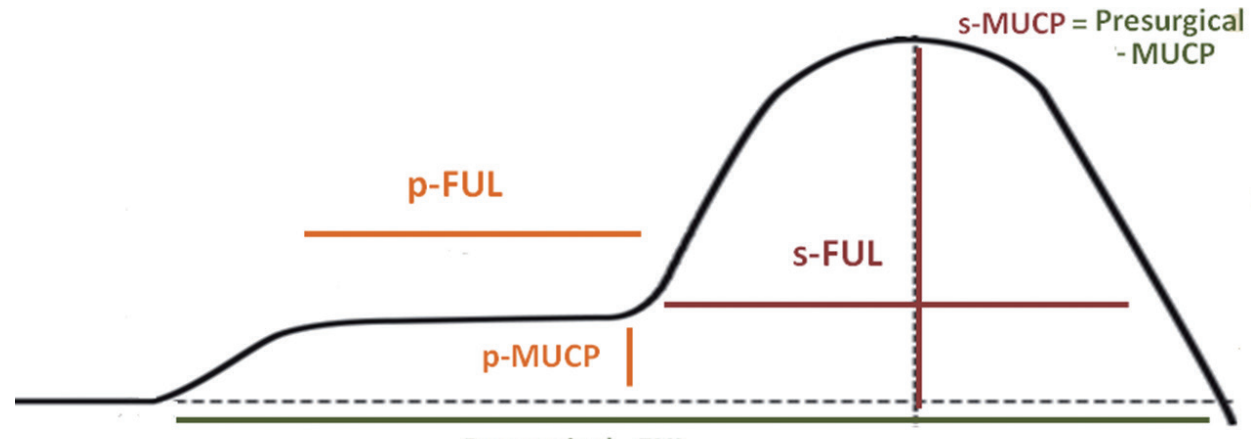

Presurgical- FUL

Fig. 1. Parameters of the urethral pressure profile: prostatic (p) and sphincter (s) components for maximum urethral closure pressure (MUCP) and functional urethral length (FUL). Presurgical MUCP and FUL were subdivided into prostatic urethra (p-MUCP and pFUL) and urethral sphincter (s-MUCP and s-FUL) values. 
Table 1. Electromyography values before and after surgery

\begin{tabular}{|c|c|c|c|c|}
\hline Variable & Continent $(\mathrm{n}=11)$ & Incontinent $(\mathrm{n}=8)$ & $\mathrm{P}$-value & Total \\
\hline \multicolumn{5}{|l|}{ MUCP } \\
\hline \multicolumn{5}{|l|}{ Pre } \\
\hline Total & $95.7(38.3)$ & $105.6(41.3)$ & 0.597 & $99.9(38.8)$ \\
\hline Prostatic & $25.9(16.2)$ & $38.0(10.5)$ & 0.066 & $31.0(15.1)$ \\
\hline Sphincter & $95.7(38.3)$ & $105.6(41.3)$ & 0.597 & $99.9(38.8)$ \\
\hline Post & $65.7(32.7)$ & $74.4(24.1)$ & 0.536 & $69.4(28.9)$ \\
\hline \multicolumn{5}{|l|}{ FUL } \\
\hline \multicolumn{5}{|l|}{ Pre } \\
\hline Total & $51.9(13.1)$ & $63.1(11.7)$ & 0.071 & $55.4(15.1)$ \\
\hline Prostatic & $26.3(17.5)$ & $28.6(11.1)$ & 0.743 & $26.6(15.2)$ \\
\hline Sphincter & $25.7(10.5)$ & $34.5(13.6)$ & 0.131 & $28.8(12.9)$ \\
\hline \multicolumn{5}{|c|}{ Wave amplitude } \\
\hline \multicolumn{5}{|l|}{ At rest } \\
\hline Pre & $286.4(84.8)$ & $262.3(75.8)$ & 0.532 & $276.2(79.9)$ \\
\hline Post & $196.9(59.9)$ & $179.0(64.6)$ & 0.542 & $189.4(60.8)$ \\
\hline \multicolumn{5}{|l|}{ Mean } \\
\hline Pre & $543.4(160.1)$ & $500.6(215.3)$ & 0.625 & $525.4(180.9)$ \\
\hline Post & $405.2(114,8)$ & $305.0(89.8)$ & 0.056 & $363.0(114.2)$ \\
\hline \multicolumn{5}{|c|}{ During stress } \\
\hline Pre & $786.9(220.7)$ & $660.7(216.3)$ & 0.232 & $733.8(222.2)$ \\
\hline Post & $615.1(184.5)$ & $432.5(141.7)$ & 0.032 & $538.2(187.9)$ \\
\hline
\end{tabular}

Values are presented as number (\%).

MUCP, maximum urethral closure pressure; FUL, functional urethral length.

Table 2. Descriptive statistics and comparison of age in relation to urinary incontinence after surgery

\begin{tabular}{rcrccc}
\hline & Incontinence & No. & Mean & $\begin{array}{c}\text { Standard } \\
\text { deviation }\end{array}$ & $\begin{array}{c}\text { Standard } \\
\text { error }\end{array}$ \\
\hline \multirow{2}{*}{ Age $(\mathrm{yr})$} & No & 11 & 63.09 & 6.07 & 1.831 \\
& Yes & 8 & 63.38 & 3.34 & 1.179 \\
\hline
\end{tabular}

$\mathrm{P}=0.906$.

divided into 2 groups: continent patients and those presenting with urinary incontinence after RP. The electromyography values included MUCP and FUL. Presurgical MUCP and FUL were subdivided into prostatic urethra ( $\mathrm{p}-\mathrm{MUCP}$ and $\mathrm{p}-\mathrm{FUL}$ ) and urethral sphincter (s-MUCP and s-FUL) values. The amplitude of waves was divided into the values at rest, during stress, and the means value. P-values were calculated to compare continent versus incontinent groups. The mean and standard deviation values are shown in Table 1.

The only presurgical variables that showed significant differ- ences between the continent and incontinent patients were $\mathrm{p}$ MUCP $(P=0.066)$ and FUL $(P=0.071)$. The postsurgical values that showed significant differences were the mean and duringstress wave amplitudes $(\mathrm{P}=0.056$ and $\mathrm{P}=0.032$, respectively).

A relationship was found between $\mathrm{p}-\mathrm{MUCP}$, presurgical FUL and $\mathrm{p}-\mathrm{FUL}$.

In all patients, prostatectomy was performed through an open approach following the Walsh technique. Age (Table 2), UDC (Table 3), and tumoral stage (Table 4) did not vary significantly in function to final incontinence. Therefore, age, UDC, tumoral stage, and surgical technique were not included in the final model because they showed no relationship with postprocedural urinary incontinence. Thus, none of these variables were confounding factors.

In the urodynamic study and the evaluation of detrusor overactivity in cystometry, $31.5 \%$ of the patients showed UDC before surgery. Of those patients, 33\% did not show UDC after RP. Of the $68.4 \%$ of patients who did not show UDC before 
Table 3. Descriptive statistics and comparison of uninhibited detrusor contractions before surgery in relation to urinary incontinence after surgery

\begin{tabular}{lccr}
\hline & \multicolumn{2}{c}{ Incontinence } & \multirow{2}{*}{ Total } \\
\cline { 2 - 3 } & No & Yes & \\
\hline Uninhibited detrusor & & & \\
contractions before surgery & & & \\
No & $9(81.8)$ & $4(50.0)$ & $13(68.4)$ \\
Yes & $2(18.2)$ & $4(50.0)$ & $6(31.6)$ \\
Total & $11(100)$ & $8(100)$ & $19(100)$ \\
\hline
\end{tabular}

Values are presented as number (\%). $\mathrm{P}=0.319$.

Table 4. Descriptive statistics and comparison of tumor stage in relation to urinary incontinence after surgery

\begin{tabular}{lccr}
\hline & \multicolumn{2}{c}{ Incontinence } & Total \\
\cline { 2 - 3 } & No & Yes & \\
\hline Tumor stage & & & \\
pT2c & $6(54.5)$ & $7(87.5)$ & $13(68.4)$ \\
pT3 & $5(45.5)$ & $1(12.5)$ & $6(31.6)$ \\
Total & $11(100)$ & $8(100)$ & $19(100)$ \\
\hline
\end{tabular}

Values are presented as number (\%).

$\mathrm{P}=0.177$.

surgery, 38.5\% showed UDC after the procedure. Hence, $63.2 \%$ (12 patients) showed the same cystometry patterns in terms of the presence of UDC before and after RP, whereas a change was recorded in $46.8 \%$ of patients.

\section{Pad Test Value Prediction From Presurgical Data}

Dependent variable: Pad test.

Independent variables: Wave amplitude (resting, during stress, and mean), MUCP, and FUL.

In the first model with presurgical MUCP and FUL (without subdivisions), presurgical FUL was used as the unique variable remaining in the model. The linear model showed a determination coefficient $\left(\mathrm{R}^{2}\right)$ of $0.289(\mathrm{P}=0.018)$. An exponential model with the variable "PAD +1 " showed an $\mathrm{R}^{2}$ of $0.233(\mathrm{P}=0.021)$. In the second model, with p-MUCP, s-MUCP, p-FUL, and sFUL, the unique variable with predictive power was s-FUL. The linear model showed an $\mathrm{R}^{2}$ of $0.340(\mathrm{P}=0.009)$. The exponential model for "Pad Test +1 " had an $\mathrm{R}^{2}$ of $0.275(\mathrm{P}=0.021)$. The quadratic model showed an $\mathrm{R}^{2}$ of $0.426(\mathrm{P}=0.012)$.
Table 5. Comparative results for the presence of urinary incontinence after radical prostatectomy between the second prediction model and incontinence observed in the pad test

\begin{tabular}{lccc}
\hline & \multicolumn{2}{c}{ Predicted } & \\
\cline { 2 - 3 } Observed & \multicolumn{2}{c}{ Incontinent } & $\begin{array}{c}\text { Successful } \\
\text { percentage }\end{array}$ \\
\cline { 2 - 3 } & No & Yes & \\
\hline Incontinent & 10 & 1 & $90.90 \%$ \\
No & 2 & 6 & $75.00 \%$ \\
Yes & & & $84.20 \%$ \\
Total percentage & & & \\
\hline
\end{tabular}

Classification of patients according to the second model for urinary incontinence prediction from presurgical data (prostatic-maximum urethral closure pressure, sphincter- maximum urethral closure pressure, prostatic-full urethral length, and sphincter-full urethral length) compared to urinary incontinence observed in the pad test.

\section{Urinary Incontinence Prediction From Presurgical Data}

The independent variable of urinary incontinence (yes/no) was built from the pad test results. The dependent variables were wave amplitude (resting, mean, and during stress), MUCP, and FUL.

If the first model was used, with presurgical MUCP and FUL (without subdivisions), the unique variable with predictive power was presurgical FUL, according to which $78.9 \%$ of the patients would be correctly classified: $81.8 \%(n=9)$ in the nonurinary incontinence group and $75 \%(n=6)$ of those with urinary incontinence (AUROC $=0.761 ; 95 \%$ confidence interval , $0.518-1.000 ; \mathrm{P}=0.058$; sensitivity $=12.5 \%)$.

Using the second model, with p-MUCP, s-MUCP, p-FUL, and s-FUL, the predictive variables were $\mathrm{p}$-MUCP and mean and during-stress wave amplitude (Table 5). The linear predictor $\eta$ was obtained from the variables of $p$-MUCP, mean wave amplitude, and during-stress wave amplitude when applying the equation:

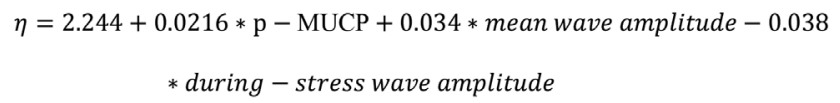

The probability of suffering from urinary incontinence after RP was obtained from a logistic regression model with the formula:

$$
p=\frac{e^{\eta}}{1+e^{\eta}}
$$

where $e^{\eta}$ represents the exponential of $\eta$.

Using this model, effective predictions were made in 16 out of 19 cases (i.e., if the model predicted no urinary incontinence, 
Table 6. Maximum urethral closure pressure (MUCP), mean and during-stress wave amplitude, and the concordance between predicted (according to the second model) and observed urinary incontinence after prostatectomy for every case

\begin{tabular}{|c|c|c|c|c|c|}
\hline \multirow{2}{*}{ MUCP } & \multicolumn{2}{|c|}{ Wave amplitude } & \multirow{2}{*}{ Percentage } & \multicolumn{2}{|c|}{ Incontinence } \\
\hline & Mean & During stress & & Observed & Predicted \\
\hline 11 & 830 & 1.000 & $1 \%$ & No & No \\
\hline 41 & 524 & 900 & $0 \%$ & No & No \\
\hline 10 & 204 & 306 & $43 \%$ & No & No \\
\hline 29 & 856 & 990 & $52 \%$ & Yes & Yes \\
\hline 12 & 600 & 1.000 & $0 \%$ & No & No \\
\hline 56 & 563 & 790 & $97 \%$ & Yes & Yes \\
\hline 54 & 619 & 970 & $13 \%$ & No & No \\
\hline 36 & 340 & 506 & $91 \%$ & Yes & Yes \\
\hline 46 & 670 & 890 & $76 \%$ & $\underline{\text { No }}$ & $\underline{\text { Yes }}$ \\
\hline 36 & 778 & 900 & $91 \%$ & Yes & Yes \\
\hline 35 & 630 & 890 & $7 \%$ & No & No \\
\hline 39 & 468 & 700 & $49 \%$ & Yes & $\underline{\text { No }}$ \\
\hline 13 & 500 & 800 & $0 \%$ & No & No \\
\hline 34 & 400 & 500 & $99 \%$ & Yes & Yes \\
\hline 29 & 500 & 700 & $25 \%$ & No & No \\
\hline 9 & 400 & 500 & $23 \%$ & No & No \\
\hline 25 & 500 & 700 & $12 \%$ & No & No \\
\hline 50 & 300 & 400 & $100 \%$ & Yes & Yes \\
\hline 24 & 300 & 500 & $20 \%$ & $\underline{\text { Yes }}$ & $\underline{\text { No }}$ \\
\hline
\end{tabular}

Cases were there was no correspondence between predicted urinary incontinence and observed urinary incontinence are underlined in bold.

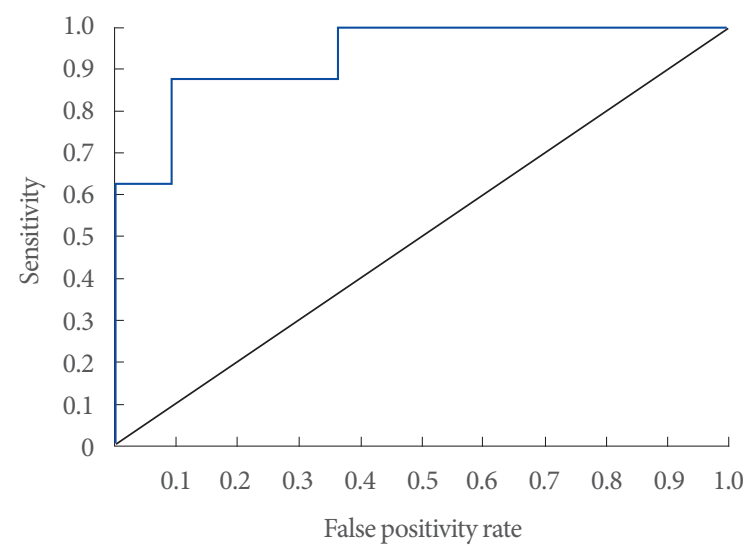

Fig. 2. ROC curves and AUROC. The false positive rate $(x)$ versus sensitivity $(y)$ for urinary incontinence prediction from presurgical data $(A U R O C=0.932 ; 95 \%$ confidence interval, 0.819 1.000; $\mathrm{P}=0.002$ ). Sensitivity equaled $87.5 \%$ for a false positive rate of $10 \%$. ROC, receiver operating characteristic; AUROC, area under the ROC curve.

thral sphincter have limitations as predictive tools separately. We tested the hypothesis that the combination of the urethral pressure profile and electromyography of the urethral sphincter there was no urinary incontinence recorded, while if the model predicted urinary incontinence, there was observed urinary incontinence). Cases were there was no correspondence between predicted urinary incontinence and observed urinary incontinence are underlined in bold in Table 6 . Only $84.2 \%$ of the patients were correctly classified: $90.9 \%(n=10)$ of those without urinary incontinence and $75 \%(n=6)$ of those with urinary incontinence. The cutoff value was set at 0.500 . The sensitivity for the prediction of urinary incontinence with this model was 87.5\% (Fig. 2).

For the urinary incontinence variable according to ICIQ-SF and the pad test, a Pearson correlation coefficient ( $r$ ) of 0.313 $(\mathrm{P}=0.192)$ was obtained. The pad test was related to the number of pads used per day, with a Spearman correlation coefficient (rs) of $0.811(\mathrm{P}<0.001)$. According to this classification, $57.9 \%$ of the patients would be continent after RP and $42.1 \%$ would present urinary incontinence.

\section{DISCUSSION}

The urethral pressure profile and electromyography of the ure- 
may be useful as a predictor of urinary incontinence after RP. The aim was to assess whether the combination of the tests resulted in an improved tool for the prediction of post-RP urinary incontinence. In that case, an improved and more reliable tool consisting of the 2 tests together with a statistical predictive model would lead to a novel and promising tool helping patients to have a clearer sense of their likelihood of suffering from permanent urinary incontinence after RP, which would substantially help them to choose between treatment modalities.

A limitation of this study is that only 19 patients were included. However, the analysis did demonstrate statistical significance. The predictive value of the combination of these 2 tests was assessed. Additionally, we did not only evaluate the total value of presurgical variables (MUCP and FUL), but we calculated fractional variables. We separated the specific values for the sphincter urethra and prostatic urethra (s-MUCP, p-MUCP, s-FUL, and p-FUL, respectively). Taking into account that MUCP is always the maximum pressure value within the urethra, the total MUCP equals the presurgical s-MUCP.

The total presurgical FUL equals the sum of s-FUL and pFUL. However, since the prostatic component is removed in surgery, postsurgical p-FUL does not exist. Therefore, the postoperative parameters only included s-MUCP and s-FUL as a whole.

Another novel factor that we took into account is the inclusion of prostatic urethra resistance. This is relevant because it belongs to the anatomical unit of the prostate involved in continence before surgery and it is removed during surgery.

In our study, $46.8 \%$ of the patients showed a change in cystometry patterns in terms of the presence of UDC before and after RP. It is possible that patients within our study in whom UDC disappeared after RP had an underdiagnosed bladder outlet obstruction due to the prostate. The data on detrusor overactivity before and after RP suggest that there was an increase in the hazard ratio for UDC after the procedure in relation to body mass index, tobacco use, oncological stage, and whether the nerve sparing technique was performed [21,22]. We did not control for some of these risk factors, which might have had the potential to confound the outcomes. These variables should be controlled in further studies.

The result that there was a relationship between the ICIQ-SF and pad test led us to build a model with the 1-hour pad test as the reference evaluation for urinary incontinence. The absence of a relationship between the ICIQ-SF and pad test would po- tentially mean that a patient with mild objective urinary incontinence may show high severity in the subjective questionnaire. Instead, the finding of a relationship between the pad test and the number of pads used means that the number of pads may give be useful for evaluating the severity of urinary incontinence.

In conclusion, the combination of the urethral pressure profile (p-MUCP) and electromyography of the urethral sphincter might be a useful prognostic predictor of post-RP urinary incontinence. The joint use of these 2 tests might be a novel tool for predicting 1 of the 2 major complications of RP. A better ability to predict whether incontinence will remain after surgery may be useful for the selection of treatment in patients with localized prostate cancer.

\section{ACKNOWLEDGEMENTS}

The authors acknowledge Enrique Francisco González Dávila (Department of Statistics and Operative Research, University of La Laguna) for his contribution to this study.

Patricia Márquez Aviar and Ana Pérez Martín, nurses of the Unit of Neurourology in the Department of Urology of the institution where the study was performed for their assistance with the experiments. The authors would also like to acknowledge Dr. Jesús Monllor Gisbert, Dr. Omar Halawa González, and Katrina Beans for their support.

\section{AUTHOR CONTRIBUTION STATEMENT}

- Conceptualization: JRT, BBM, MFRP, DCD

- Data curation: JRT, $M S, D C D$

- Formal analysis: JRT, BBM

- Methodology: JRT, MFRP, DCD

- Project administration: JRT, BBM, MS, MFRP

- Visualization: JRT, BBM, MS

- Writing-original draft: $J R T, B B M$

-Writing-review \& editing: JRT, $B B M, M F R P, D C D$

\section{ORCID}

Jonathan Rodríguez Talavera

Begoña Ballesta Martínez

Melania Santacruz Perez

Manuel Felipe Ravina Pisaca

David Castro Díaz
0000-0001-8699-4226

0000-0001-8567-0545

$0000-0002-8147-2848$

0000-0002-7681-2246

0000-0002-4484-9159 


\section{REFERENCES}

1. Hamdy FC, Donovan JL, Lane JA, Mason M, Metcalfe C, Holding P, et al. 10-Year outcomes after monitoring, surgery, or radiotherapy for localized prostate cancer. N Engl J Med 2016;375:1415-24.

2. Walsh PC, Partin AW, Epstein JI. Cancer control and quality of life following anatomical radical retropubic prostatectomy: results at 10 years. J Urol 1994;152(5 Pt 2):1831-6.

3. Litwin MS, Pasta DJ, Yu J, Stoddard ML, Flanders SC. Urinary function and bother after radical prostatectomy or radiation for prostate cancer: a longitudinal, multivariate quality of life analysis from the Cancer of the Prostate Strategic Urologic Research Endeavor. J Urol 2000;164:1973-7.

4. Aanestad O, Flink R, Häggman M, Norlén BJ. Interference pattern in the urethral sphincter: a quantitative electromyographic study in patients before and after radical retropubic prostatectomy. Scand J Urol Nephrol 1998;32:378-82.

5. Chao R, Mayo ME. Incontinence after radical prostatectomy: detrusor or sphincter causes. J Urol 1995;154:16-8.

6. Dubbelman YD, Bosch JL. Urethral sphincter function before and after radical prostatectomy: Systematic review of the prognostic value of various assessment techniques. Neurourol Urodyn 2013; 32:957-63.

7. Blaivas JG, Labib KL, Bauer SB, Retik AB. A new approach to electromyography of the external urethral sphincter. J Urol 1977;117: 773-7.

8. Brown M, Wickham JE. The urethral pressure profile. Br J Urol 1969; 41:211-7.

9. Edwards L, Malvern J. The urethral pressure profile: theoretical considerations and clinical application. Br J Urol 1974;46:325-35.

10. Liu S, Christmas TJ, Nagendran K, Kirby RS. Sphincter electromyography in patients after radical prostatectomy and cystoprostatectomy. Br J Urol 1992;69:397-403.

11. Nguyen L, Jhaveri J, Tewari A. Surgical technique to overcome anatomical shortcoming: balancing post-prostatectomy continence outcomes of urethral sphincter lengths on preoperative magnetic resonance imaging. J Urol 2008;179:1907-11.

12. Mungovan SF, Sandhu JS, Akin O, Smart NA, Graham PL, Patel MI. Preoperative membranous urethral length measurement and continence recovery following radical prostatectomy: a systematic review and meta-analysis. Eur Urol 2017;71:368-78.

13. Ikarashi D, Kato Y, Kanehira M, Takata R, Ito A, Onoda M, et al. Appropriate preoperative membranous urethral length predicts recovery of urinary continence after robot-assisted laparoscopic prostatectomy. World J Surg Oncol 2018;16:224.

14. Rico L, Vitagliano G, López FM, Rios Pita H, Bonanno N, Nazar $\mathrm{ME}$, et al. Urinary continence prediction after laparoscopic radical prostatectomy according to preoperative urethral length measurement in multiparametric prostate resonance. Arch Esp Urol 2020; 73:777-83.

15. Alyaev Y, Ternovoy S, Bezrukov E, Grigorev N, Sinitsyn V, Morozov $\mathrm{S}$. Functional length of membranous urethra as a predictor of urinary incontinence after radical prostatectomy. Eur Urol Suppl 2007; 6:152.

16. Pfister C, Cappele O, Dunet F, Bugel H, Grise P. Assessment of the intrinsic urethral sphincter component function in postprostatectomy urinary incontinence. Neurourol Urodyn 2002;21:194-7.

17. Bentzon DN, Graugaard-Jensen C, Borre M. Urethral pressure profile 6 months after radical prostatectomy may be diagnostic of sphincteric incontinence: preliminary data after 12 months' followup. Scand J Urol Nephrol 2009;43:114-8.

18. Mungovan SF, Sandhu JS, Akin O, Smart NA, Graham PL, Patel MI. Preoperative membranous urethral length measurement and continence recovery following radical prostatectomy: a systematic review and meta-analysis. Eur Urol 2017;71:368-78.

19. Mouritsen L, Berild G, Hertz J. Comparison of different methods for quantification of urinary leakage in incontinent women. Neurourol Urodyn 1989;8:579-86.

20. Hammerer P, Huland H. Urodynamic evaluation of changes in urinary control after radical retropubic prostatectomy. J Urol 1997; 157:233-6.

21. Hosier GW, Tennankore KK, Himmelman JG, Gajewski J, Cox AR. Overactive bladder and storage lower urinary tract symptoms following radical prostatectomy. Urology 2016;94:193-7.

22. Kleinhans B, Gerharz E, Melekos M, Weingärtner K, Kälble T, Riedmiller $\mathrm{H}$. Changes of urodynamic findings after radical retropubic prostatectomy. Eur Urol 1999;35:217-21. 